\title{
T CELL MECHANISMS IN EXPERIMENTAL AUTOIMMUNE UVEORETINITIS: SUSCEPTIBILITY IS A FUNCTION OF THE CYTOKINE RESPONSE PROFILE
}

\author{
RACHEL R. CASPI ${ }^{1}$, BING SUN ${ }^{1}$, RAJEEV K. AGARWAL ${ }^{1}$, PHYLLIS B. SILVER ${ }^{1}$, \\ LUIZ V. RIZZO ${ }^{1}$, CHI-CHAO CHAN ${ }^{1}$, BARBARA WIGGERT ${ }^{2}$ and RONALD L. WILDER ${ }^{3}$ \\ Bethesda, Maryland
}

\begin{abstract}
SUMMARY
This study addresses the question whether susceptibility versus resistance to experimental autoimmune uveoretinitis (EAU) is connected to a Th1-type (interferongamma high, interleukin-4 low), versus a Th2-type (IFN- $\gamma$ low, IL-4 high) response. Primed lymph node cells of susceptible Lewis rats produced IFN- $\gamma$ in response to antigen in culture and transferred EAU to syngeneic recipients, whereas lymph node cells of resistant F344 rats made no IFN- $\gamma$ and did not transfer disease. Reversal of the disease pattern, by treatment of F344 rats with $B$. pertussis toxin and immunisation of Lewis rats with antigen in incomplete Freund's adjuvant, resulted in a parallel reversal of these response patterns. Neither strain produced significant IL-4 responses. A study of the response patterns in mice confirmed that high Th1 responders were susceptible, whereas low Th1 responders and Th2 responders were resistant. We conclude that susceptibility to EAU is connected with a Th1-dominant response, but resistance can involve either a 'null', F344-like response (Th1-low/Th2-low) or a Th2dominant response.
\end{abstract}

Experimental autoimmune uveoretinitis (EAU) represents a series of autoimmune or immunemediated human diseases that affect the posterior segment of the eye and result in significant visual deficit. EAU is a T-cell-mediated disease that can be adoptively transferred to naive syngeneic recipients with $\mathrm{CD}^{+} \mathrm{T}$ lymphocyte lines specific to uveitogenic retinal antigens. These lines are typically Th1-like

From: ${ }^{1}$ Laboratory of Immunology and ${ }^{2}$ Laboratory of Retinal Cell and Molecular Biology, National Eye Institute, Bethesda; ${ }^{3}$ Arthritis and Rheumatism Branch, National Institute of Arthritis and Musculoskeletal and Skin Diseases, NIH, Bethesda, Maryland, USA.

Correspondence to: Rachel R. Caspi, PhD, Laboratory of Immunology, NEI, NIH Bg. 10, Room 10N222, 10 Center Drive MSC 1858, Bethesda, MD 20892-1858, USA. cells that produce interferon-gamma (IFN- $\gamma$ ) but not interleukin-4 (IL-4), or Th0-like cells that produce both IFN- $\gamma$ and IL-4 and that after adoptive transfer shift to a Th1-like phenotype in vivo. ${ }^{1,2}$ This indicates that the uveitogenic effector $\mathrm{T}$ cell is a Th1-like lymphocyte. In contrast, we and others have presented evidence that a Th2-type response to autoantigens can confer protection from autoimmune disease. ${ }^{3,4}$ We therefore set out to examine whether a Th1-dominant response pattern to the uveitogenic antigen might be associated with susceptibility to EAU, and conversely, whether resistant genotypes would have a Th2-like response pattern. Here we review the pertinent evidence obtained from studies in rat and mouse strains with different susceptibilities to EAU. The results point to the conclusion that an EAU-susceptible strain is likely to be a high Th1 responder. An EAU-resistant strain, on the other hand, is likely to be a low Th1 responder. The EAUresistant genotype can, but does not have to be, a dominant Th2 responder to the uveitogenic antigen. This indicates that control of the pathogenic Th1 response can be achieved through more than one regulatory pathway.

\section{Animals \\ MATERIALS AND METHODS}

Rats and mice between 5 and 8 weeks of age were purchased from Harlan Sprague Dawley (Indianapolis, IN) and Jackson Labs (Bar Harbor, ME). Animals were housed under specific pathogen-free conditions and were treated according to ARVO and institutional guidelines.

\section{Antigens and Reagents}

Bovine interphotoreceptor retinoid-binding protein (IRBP) was purified from retinal tissue as described 
previously. ${ }^{5}$ Peptide R16 (ADGSSWEGVGVVPDV, residues 1177-1191) derived from it was synthesised as described previously. ${ }^{6}$ Mouse IFN- $\gamma$ and IL-4 protein were measured by ELISA. ${ }^{3}$ Rat IFN- $\gamma$ was measured by ELISA using a commercial kit (3281SA, GIBCO-BRL). Cytokine mRNAs were measured by quantitative reverse transcriptase-polymerase chain reaction (RT-PCR) as described previously. ${ }^{7}$

\section{Induction and Grading of EAU}

Mice were immunised with $100 \mu \mathrm{g}$ IRBP in complete Freund's adjuvant (CFA) and $1.0 \mu \mathrm{g}$ B. pertussis toxin (PTX), whereas rats received $30 \mu \mathrm{g}$ R16 in CFA, with or without $0.3 \mu \mathrm{g}$ PTX, as described previously. ${ }^{8,9}$ In some experiments Lewis rats were immunised with R16 in incomplete Freund's adjuvant (IFA). In some experiments EAU was induced in rats by adoptive transfer of lymph node cells or spleen cells from immunised donors to recipients of the same genotype. ${ }^{8}$ Eyes were collected 16 days after immunisation, or 13 days after adoptive transfer. H\&E-stained methacrylate sections were graded by histopathology on a scale of 0 to 4 as described previously. ${ }^{10}$

\section{Culture of Lymphocytes for Proliferation, for Cytokine Assays and for Adoptive Transfer}

Lymph node or spleen cells were obtained from R16-immunised donor rats 12-14 days after immunisation and were stimulated in culture with R16 peptide, as described previously. ${ }^{8}$ Cells for mRNA measurement were collected after 24 hours in culture. Supernatants for cytokine protein assay were collected at 48 hours. Cells for adoptive transfer were collected after 3 days of culture.

\section{RESULTS AND DISCUSSION}

Susceptible Lewis Rats are High Th1 Responders, Resistant F344 Rats are Low Th1 Responders

Lewis and F344 rats share the same MHC class II, and consequently both recognise the same uveitogenic epitopes; however, Lewis rats are EAUsusceptible and F344 rats are EAU-resistant. Lewis rats immunised with R16 developed disease, typically of grade 1 to 2, after 9-11 days. F344 rats were

Table I. Susceptibility to EAU versus pathogenicity of primed lymphocytes and antigen-specific cytokine profiles in Lewis and F344 rats

\begin{tabular}{lcc}
\hline & Lewis & F344 \\
\cline { 2 - 3 } RT1 (MHC) & 1 & $1^{\mathrm{v} 1}$ \\
RT1B (class II) & 1 & 1 \\
\hline EAU scores & +++ & \pm \\
Adoptive transfer & +++ & \pm \\
IFN $\gamma$ & +++ & \pm \\
IL-4 & \pm & \pm \\
Th1/Th2 & Th1 & $?$ \\
\hline Adapted from & &
\end{tabular}

Adapted from Caspi et al. ${ }^{8}$ resistant and did not develop disease even after 3 or 4 weeks. Analysis of the antigen-specific responses of draining lymph node cells from these animals showed that both displayed proliferation to the immunising peptide, indicating that primed cells were being generated by both strains. However, they differed in antigen-specific production of IFN- $\gamma$ and in the ability to adoptively transfer disease to naive recipients of the appropriate genotype. While primed lymphoid cells of Lewis rats produced up to $4 \mathrm{ng} / \mathrm{ml}$ of IFN- $\gamma$ protein in response to R16 in culture, F344 rats had an undetectable IFN- $\gamma$ response. Analysis of the IL-4 mRNA of the two strains by quantitative RT-PCR showed that neither strain produced a significant IL-4 response to R16. Thus, while the Lewis rats responded in a typical Th1-like pattern, the F344 rats displayed a low Th1-type, but also a low Th2-type, response. Adoptive transfer of the primed lymph node cells after culture with R16 to syngeneic recipients showed that as few as $10 \times 10^{6}$ primed lymph node cells from Lewis donors caused low-grade EAU after 5-6 days in 3 of 5 recipients, and all recipients of $25 \times 10^{6}$ or more cells developed maximal disease. In contrast, none of the F344 recipients of $50 \times 10^{6}$ cells developed disease, and 2 of 6 F344 rats that received $100 \times 10^{6}$ cells developed low-grade EAU. The response patterns of the two rat strains are summarised in Table I.

The difference in antigen-specific IFN- $\gamma$ production between Lewis and F344 rats, together with the difference by a factor of 10 in the ability of their primed lymphoid cells to transfer disease, indicated that while the Lewis rats efficiently generated uveitogenic Th1 effector cells, the F344 rats were somehow able to prevent their development. Since the F344 rats did not make a detectable IL-4 response to R16, they were apparently able to do that through a mechanism that does not involve generation of a dominant $\mathrm{Th} 2$ response.

\section{Reversing the Susceptibility Pattern Results in a Parallel Shift in Response Profile}

If generation of a Th1-high response is indeed associated with disease, then an immunisation protocol that does not provoke disease in the Lewis rats should downregulate their IFN- $\gamma$ response, and primed lymphocytes taken from these rats should

Table II. Reversal of susceptibility pattern in Lewis and F344 rats reverses the patterns of lymphoid cell pathogenicity and antigen-specific cytokine production

\begin{tabular}{lcc}
\hline & $\begin{array}{c}\text { Lewis rats } \\
\text { immunised with } \\
\text { R16 in IFA }\end{array}$ & $\begin{array}{c}\text { F344 rats } \\
\text { given PTX at } \\
\text { immunisation }\end{array}$ \\
\hline EAU scores & \pm & ++ \\
Adoptive transfer & - & ++ \\
IFN- $\gamma$ & + & +++ \\
Th1/Th2 & $?$ & Th1 \\
\hline
\end{tabular}

Adapted from Caspi et al. $^{8}$ 
Table III. Susceptibility to EAU versus antigen-specific cytokine response profile and antibody isotype in different strains of mice

\begin{tabular}{|c|c|c|c|c|c|c|}
\hline & $\mathrm{A} / \mathrm{J}$ & B10.A & AKR & $\mathrm{BALB} / \mathrm{k}$ & $\mathrm{BALB} / \mathrm{c}$ & $\mathrm{C} 57 \mathrm{BL} / 10$ \\
\hline H-2 (MHC) & a & $\mathrm{a}$ & $\mathrm{k}$ & $\mathrm{k}$ & d & b \\
\hline I-A (class II) & $\mathrm{k}$ & $\mathrm{k}$ & $\mathrm{k}$ & $\mathrm{k}$ & d & $\mathrm{b}$ \\
\hline EAU scores & + & +++ & - & ++ & - & ++ \\
\hline IFN- $\gamma$ & \pm & +++ & - & ++ & - & +++ \\
\hline IL-4 & $\bar{t}$ & - & - & - & ++ & - \\
\hline TGF- $\beta$ & + & ++ & ++ & + & \pm & ++ \\
\hline Predominant $\mathrm{Ab}$ isotype & $\mathrm{IgG} 2 \mathrm{a}$ & $\mathrm{IgG} 2 \mathrm{a}$ & $\operatorname{IgG} 2 \mathrm{a}$ & $\operatorname{IgG} 2 \mathrm{a}$ or $\operatorname{IgG} 1^{\mathrm{a}}$ & IgG1 & $\operatorname{IgG} 2 \mathrm{a}$ \\
\hline Th1/Th2 & $?$ & Th1 & $?$ & Th1 & Th2 & Th1 \\
\hline
\end{tabular}

Adapted from Sun et al. $^{9}$

${ }^{a}$ Varies in individual mice.

be unable to adoptively transfer EAU. Conversely, an immunisation protocol that elicits disease in F344 rats should upregulate their IFN- $\gamma$ response, and yield a primed lymphoid cell population that efficiently transfers disease. In order to test this hypothesis, F344 rats were treated concurrently with immunisation with PTX, which is known to overcome resistance to autoimmunity in some cases but whose mode of action is not well understood. On the other hand, Lewis rats were immunised with peptide emulsified in IFA, known to be less efficient than CFA in promoting cell-mediated immunity.

PTX treatment abrogated the resistance of F344 rats, and 7 of 10 developed EAU within 14 days of immunisation with R16. Their primed lymph node cells produced nanogram amounts of IFN- $\gamma$ in response to R16 in culture. Furthermore, all recipients of primed splenocytes from PTX-treated donors, but none of the recipients of cells from untreated donors, developed maximal EAU. Conversely, immunisation of Lewis rats with R16 in IFA resulted in little or no disease. Their primed cells produced less than one-quarter the amount of IFN- $\gamma$ compared with CFA-immunised Lewis rats in response to the peptide. None of the recipients of splenocytes from IFA-immunised donors developed EAU. However, addition of IL-12 (known to promote Th1 development) to the culture of cells from IFA-immunised Lewis donors fully restored their ability to produce IFN- $\gamma$ and to transfer disease. The response patterns are summarised in Table II. These results confirm the hypothesis that a Th1-high response is tightly linked to pathogenicity, and a Th1-low response is associated with resistance. Furthermore, these results point out, for the first time, that PTX overcomes resistance to cell-mediated autoimmunity at least in part through upregulation of the Th1 response.

\section{Susceptibility Versus Th1/Th2 Response Profiles in Mice}

Mice generally require PTX treatment to develop EAU. Nevertheless, despite such treatment, some strains remain conspicuously resistant to disease. It was therefore interesting to see whether such continued EAU resistance in the face of PTX treatment remains associated with a Th1-low cytokine profile. A series of six strains of known susceptibility to EAU were immunised with IRBP in CFA and were treated with PTX, and their cytokine responses to IRBP as well as the anti-IRBP serum antibody isotypes were tested. The mice differed in class II haplotypes and consequently in their recognition of pathogenic epitopes; therefore, the whole IRBP molecule was used for immunisation. Because IFN- $\gamma$ is the switch factor for IgG2a, the predominance of this isotype suggests the presence of a Th1 response. Conversely, IL-4 is the switch factor for IgG1, and predominance of this isotype is considered indicative of a Th2 response.

The response patterns of the various mouse strains, as determined 16 days after immunisation, are shown in Table III. In general, strains with more than a minimal EAU susceptibility $(++$ and higher) produced abundant IFN- $\gamma$ to IRBP in culture, but no IL-4, and had anti-IRBP antibodies of the IgG2a isotype, supportive of a Th1-dominant response. EAU-resistant strains, on the other hand, showed several distinct response patterns. BALB/c mice behaved like typical Th2-dominant responders, making IL-4 but no IFN- $\gamma$ to IRBP in culture, and having a predominantly IgG1 antibody response. This strain has been shown by others to make preferentially Th2-type responses to microbial antigens. ${ }^{11}$ AKR mice, also highly resistant to disease, produced no detectable IFN- $\gamma$ or IL-4, reminiscent of the 'null' response of F344 rats. Nevertheless, these mice had a predominance of IgG2a antibodies, indicating that at some earlier time in vivo they must have produced IFN- $\gamma$. Interestingly, AKR mice produced abundant transforming growth factor beta (TGF- $\beta$ ) which, in the absence of a dominant Th1 response, might have contributed to their EAUresistant phenotype. An intermediate phenotype was displayed by $\mathrm{A} / \mathrm{J}$ mice. These mice developed minimal EAU and produced an IgG2a-predominant antibody response. They produced moderate amounts of IL-4 to IRBP in culture, and had an IFN- $\gamma$ response detectable at the mRNA level, possibly indicative of a Th0-like cytokine response profile. Interestingly, $\mathrm{A} / \mathrm{J}$ mice produced rather 
meagre amounts of TGF- $\beta$, which may have permitted some limited expression of disease despite lack of a dominant Th1 response to IRBP.

In summary, these results point to the conclusion that susceptibility to EAU is associated with a Th1dominant response. A state of resistance to disease is associated with a Th1-low response, and can apparently be achieved through more than one pathway. Some resistant genotypes display a dominant $\mathrm{Th} 2$ response pattern to the uveitogen, whereas others have a Th0-like response, or a 'null' response that is low in both Th1-type and Th2-type cytokines. Additional factors (either anti-inflammatory such as TGF- $\beta$ or pro-inflammatory), that might be superimposed on the Th1/Th2 response pattern, contribute to the complex nature of the regulatory mechanisms that determine susceptibility or resistance to ocular autoimmune disease.

Key words: T lymphocytes, Autoimmunity, Cytokines, Experimental autoimmune uveoretinitis, Uveitis.

\section{REFERENCES}

1. Savion S, Oddo S, Grover S, Caspi RR. Uveitogenic T lymphocytes in the rat: pathogenicity vs lymphokine production, adhesion molecules and surface antigen expression. J Neuroimmunol 1994;55:35-44.

2. Rizzo LV, Silver P, Wiggert B, Hakim F, Gazzinelli RT, Chan CC, Caspi RR. Establishment and characterization of a murine $\mathrm{CD}^{+}{ }^{+} \mathrm{T}$ cell line and clone that induce experimental autoimmune uveoretinitis in B10.A mice. J Immunol 1996;156:1654-60.

3. Rizzo LV, Miller-Rivero NE, Chan CC, Wiggert B,
Nussenblatt RB, Caspi RR. Interleukin-2 treatment potentiates induction of oral tolerance in a murine model of autoimmunity. J Clin Invest 1994;94:1668-72.

4. Rizzo LV, Caspi RR. Immunotolerance and prevention of ocular autoimmune disease. Curr Eye Res 1995;14:857-64.

5. Pepperberg DR, Okajima TL, Ripps H, Chader GJ, Wiggert B. Functional properties of interphotoreceptor retinoid-binding protein. Photochem Photobiol 1991; 54:1057-60.

6. Sanui H, Redmond TM, Kotake S, Wiggert B, Hu LH, Margalit $\mathrm{H}$, et al. Identification of an immunodominant and highly immunopathogenic determinant in the retinal interphotoreceptor retinoid-binding protein (IRBP). J Exp Med 1989;169:1947-60.

7. Sun B, Wells J, Goldmuntz E, Silver P, Remmers EF, Wilder RL, Caspi RR. A simplified competitive RTPCR method for measuring rat IFN- $\gamma$ mRNA expression. J Immunol Methods 1996;195:139-48.

8. Caspi RR, Silver PB, Chan CC, Sun B, Agarwal RK, Wells $\mathrm{J}$, et al. Genetic susceptibility to experimental autoimmune uveoretinitis (EAU) in the rat is associated with an elevated Th1 response. J Immunol 1996; 157:2668-75.

9. Sun B, Sun S-H, Rizzo LV, Chan C-C, Wilder RL, Caspi RR. Genetic susceptibility to EAU involves more than a predisposition to generate a Th1- or Th2like response. (Submitted for publication.)

10. Caspi RR. Experimental autoimmune uveoretinitis: rat and mouse. In: Cohen I, Miller A, editors. Autoimmune disease models: A guidebook. New York: Academic Press, 1994.

11. Reiner SL, Locksley RM. The regulation of immunity to Leishmania major. Annu Rev Immunol 1995; 13:151-77. 